\title{
Effect of Nursing Psychological Support and Teaching Physiotherapy Guideline on Improving Pain Level for Patients with Temporomandibular Joint Disorders
}

\author{
Fatma Gareh Ahmed ${ }^{1}$, Salah El-Dein Gaber Shaltout ${ }^{2}$, Magda Ahmed Mohammed ${ }^{3}$ \& Sahra Zaki Azer ${ }^{4}$. \\ 1 . \\ 2 . \\ Assistant lecturer in Medical Surgical Nursing Department, Faculty of Nursing, Assiut University, Egypt \\ 2. Professor of Oral and Maxillofacial Surgery, Faculty of Medicine, Assiut University, Egypt \\ 3. Professor of Medical Surgical Nursing, Faculty of Nursing, Assiut University, Egypt \\ 4. Assistant Professor of Medical Surgical Nursing, Faculty of Nursing, Assiut University, Egypt
}

\begin{abstract}
Stress and temporomandibular joint (TMJ) are often linked to each other. The symptoms of stress manifest in physical ways, often leading to a TMJ disorders and can cause jaw tension or pain. Physiotherapy treatment is very effective in relieving and managing temporomandibular joint disorders (TMJDs), even when the symptoms are long-standing and severe. Aim: To evaluate the effect of nursing psychological support and teaching physiotherapy guideline on improving pain level for patients with TMJDs. Research design: Pre/post-test research design was utilized on 50 adult patients with TMJDs. Setting: The study was conducted in the maxillofacial surgery outpatient clinic at Assiut University Hospital. Tools: Three tools were used, I) Structured questionnaire, II) psychological state assessment and III) universal pain assessment. Results: About half of the study group their age range between 18-29 years old, with mean of $(29.12 \pm 9.82)$ and about three quarter were females. There were statistically significant differences for the study group as regard psychological state and universal pain assessment. Conclusion: It was concluded that nursing psychological support and teaching physiotherapy are an important factors in the treatment of temporomandibular joint disorders. Recommendations: A written teaching guideline should be available for patients in simplified term and containing simple pictures.
\end{abstract}

\section{Keywords: Disorders, Guideline, Nursing, Physiotherapy, Psychological Support, Teaching \& Temporomandibular Joint.}

\section{Introduction}

The temporomandibular joint (TMJ) is one of the most complex joints in the human body and it is responsible for opening and closing movements of the mouth, protrusion, retraction and lateral deviation movements of the mandible on the temporal bone. It is an important structure, because its function is directly involves communication, emotional expression and feeding (Augusto et al., 2016).

Temporomandibular joint disorders (TMJDs) are a collective term used to describe a group of related disorders involving the temporomandibular joints (TMJs), masticatory muscles and occlusion. The most important feature is pain, followed by restricted mandibular movement and noises from the temporomandibular joints (TMJs) during jaw movement (Okeson, 2019). The pain often causes spasm in the adjacent muscles, which are attached to the bones of the skull, face and jaws and pain can be felt at the side of the head (the temple), cheek, lower jaw, and teeth. Although the pain is generally the defining characteristic of TMJDs (De Kanter et al., 2018).

The etiology of TMJDs is multidimensional: biomechanical, neuromuscular, bio-psychosocial and biological factors may contribute to the disorder.
Occlusal overloading and parafunctions (bruxism) are frequently involved as biomechanical factors; increased levels of estrogen hormones are considered biological factors affecting the temporomandibular joint. Among bio-psychosocial factors, stress, anxiety or depression, were frequently encountered (Chisnoiu et al., 2015).

Temporomandibular joint disorders patients exhibit a variety of psychosocial and behavioral characteristics including increased somatization, stress, anxiety and depression. Patients often suffer from marked degrees of stress in daily life and so high levels of stress can cause patients to unconsciously clench their teeth and tighten their jaw muscles, creating added pressure and strain in the joints and muscles of jaw and face. Muscle-related disorders have increased severity of pain and suffer from enhanced psychological distress (Salameh et al., 2015).

Pain and discomfort associated with TMJ disorders is temporary and can be relieved with self-managed care or nonsurgical treatments. Common treatments include psychosocial interventions like cognitive behavioral therapy and using relaxation techniques, physical therapy, occlusal splints, and pain medication or others (Gil-Martínez et al., 2018). 
Nurse play an important role in teaching patients physiotherapy including (eg, joint mobilization/manipulations, soft-tissue mobilization and stabilization exercises, massage and moist warm towels) to relieve pain, reduce inflammation, and restore motor function. With appropriate physiotherapy most patients will see a significant improvement in their symptoms within 3 to 6 weeks. It is also important to treat any associated neck pain and headaches. Posture correction is essential and should address head, neck, shoulder and tongue position. The patient should be taught exercises to improve coordination, stability and alignment of the jaw (Paço et al., 2016).

Also psychological support and teaching stress management programs include relaxation techniques such as yoga, massage, meditation, guided imagery, and slow and deep breathing exercises may be useful in calming TMJ disorders pain. While following these techniques, it is also important to avoid activities or habits that may worsen TMJ disorders, such as chewing gum, clenching the jaw, and cradling the phone between the ear and the shoulder, which may irritate the muscles of the jaw and neck (Jain et al., 2016).

\section{Test evidence of the guideline}

Temporomandibular joint disorders (TMJDs) are one of the common disorders in the maxillofacial region. From the researcher's clinical experience in the maxillofacial surgical unit at Assuit University Hospital it was observed that the patients who complain from TMJDs need special nursing teaching guideline includes psychological support and physiotherapy to improve psychological state and minimize pain so this study will be conducted to help in care of patients with TMJDs.

\section{Aim of the study}

To evaluate the effect of nursing psychological support and teaching physiotherapy guideline on improving pain level for patients with TMJDs.

\section{Research Hypothesis}

The current study hypothesized that the complain of the patient (as pain) will be improved after application of the nursing psychological support and teaching physiotherapy guideline.

\section{Subjects \& Method \\ Research design:}

Pre / post-test research design was utilized in this study.

\section{Technical design}

Setting:

The study was conducted in the maxillofacial surgery outpatient clinic at Assiut University Hospital. The outpatient clinics consist of 3 floors. The maxillofacial surgery outpatient clinic was in the first floor and it was consist of 2 rooms, one room for examination and the other room for dressing.

\section{Subjects}

Sample of 50 adult patients of both sexes in maxillofacial surgery outpatient clinic at Assiut University Hospital, age ranges from 18 to 65 years old and acute TMJDs where symptoms last for less than 3 months were included.

\section{Exclusion criteria}

- Chronic TMJDs where symptoms last for more than 3 months.

- Ankylosis of TMJ.

- History of dislocation or previous surgery of TMJ.

- Malignant tumor of the face and jaw.

- Systemic diseases that may have influence on the TMJ as diabetes mellitus or intra-oral lesion that may affect the mechanics of the TMJ.

Sample size; was calculated statistically by power analysis with precision level $5 \%$ at confidence level $95 \% \& \mathrm{P}<0.05$ and the patients flow rate (About 200 cases according to hospital record 2017) and the sample was calculated to be 50 patients.

Tools:

Three tools were utilized to collect data for this study:

Tool (I): A structured questionnaire: To assess demographic data and patient's medical data developed by the researcher based on literature review.

This tool consists of two parts:

Part (1): Demographic data for patients as (age, gender and level of education......etc.).

Part (2): Patient's medical data: The presence of trauma, previous surgery (dental implants and open reduction internal fixation), and/or repetitive trauma, migraine, headaches, earaches or tinnitus, fibromyalgia, osteoarthritis, rheumatoid arthritis ...etc.).

Tool (II): Psychological State Assessment: Using perceived stress scale (PSS) it consists of 10 items (Cohen et al., 1983). The questions in the PSS ask about feelings and thoughts during the last month. PSS scores are obtained using Likert scale $(0=$ never, 1 = almost never, 2 = sometimes, 3 = fairly often, and 4 = very often).

Responses are to be reversed (e.g., $0=4,1=3,2=2$, $3=1$, and $4=0$ ) to the four positively stated items (items 4, 5, 7, and 8) and then summing across all scale items. It was done pre implementation of the nursing psychological support and teaching physiotherapy guideline during $1^{\text {st }}$ interview at 
maxillofacial surgery outpatient clinic at Assuit University Hospital and after 4 weeks from $1^{\text {st }}$ interview post implementation of the nursing psychological support and teaching physiotherapy guideline.

Individual scores on the PSS can range from 0 to 40 with higher scores indicating higher perceived stress. Scores ranging from 0-13 was considered low stress, from 14-26 was considered moderate stress and from 27-40 was considered high perceived stress.

Tool (III): Universal Pain Assessment: To assess pain level by using faces or behavioral observations to interpret expressed pain when patients cannot communicate their pain intensity (Macres et al., 2013). Using universal pain assessment tool (0-10 Numeric Pain Intensity Scale and Wong-Baker FACES Pain Rating Scale). It was done pre implementation of the nursing psychological support and teaching physiotherapy guideline during $1^{\text {st }}$ interview at maxillofacial surgery outpatient clinic at Assuit University Hospital and after 4 weeks from $1^{\text {st }}$ interview post implementation of the nursing psychological support and teaching physiotherapy guideline.

\section{Scoring system}

$0=$ No pain $\rightarrow$ patient is alert, very happy because he doesn't hurt at all and there is no pain with activity.

$1-3=$ Mild pain $\rightarrow$ patient is no humor, serious, flat and pain tolerable and can be ignored with activity. 4-6 $=$ Moderate pain $\rightarrow$ patient facial grimace is furrowed brow, pursed lips and holding breath. Pain interferes with tasks and concentration.

$7-9=$ Severe pain $\rightarrow$ patient facial grimace is slow blink, open mouth and pain interferes with basic needs.

$10=$ Worst pain $\rightarrow$ patient facial grimace is eye closing, moaning and crying. Bed rest required.

\section{Procedure}

This study was carried out in three phases:

\section{The preparatory phase}

During this phase the researchers conducted the assessment process for the number of cases admitted in the maxillofacial surgery outpatient clinic at Assiut University Hospital.

The research was approved from faculty of nursing ethics committee. An official letter was issued from the Dean of the Faculty of Nursing to the Head of Maxillofacial Surgery outpatient clinic at Assiut University Hospital explaining the purpose of the study and requesting their permission for collecting the data.

A review of current and past, local and international related literature in the various aspects using books, articles, periodicals and magazines were done. The nursing psychological support and teaching physiotherapy guideline was prepared in simple Arabic language with simple photo illustrations.

Content validity was done by 5 expertise $(2$ medical staff from Maxillofacial Surgery department) \& (3 nursing staff) from the medical-surgical nursing field who reviewed the tool for clarity, relevance, comprehensiveness, understanding and applicability. Minor modifications were required and correction was carried out accordingly. The reliability of (Tool II \& Tool III) were confirmed for consistency by cronbach's alpha coefficient (alpha $=0.78 \&$ 0.829) respectively.

A pilot study on (10\%) 5 patients was conducted during April 2018 in order to test the clarity and applicability of the tools. According to this pilot study, the required modifications were made. Those patients who were involved in the pilot study weren't included in the study.

\section{Implementation phase}

Data collection covered a period of 8 months starting from June 2018 till the end of February 2019. Once permission was granted to proceed with the proposed study, the investigator initiated data collection, name of potential patients who have admitted to the maxillofacial surgery outpatient clinic and who met the criteria were included.

First, the researcher greeted the patients, introduced herself and purpose of study was explained by the researchers to patients who agreed to participate in the study prior to any data collection. The researcher took the patients' telephone number at the first contact to determine the time of appointments in order to complete data collection process (after 4 weeks).

After taking the patient oral agreement for voluntary participation in the study, each patient was interviewed individually after receiving medical management and asked to answer interview questionnaire sheet. Initial assessment of psychological state and universal pain assessment were done and recorded.

Then the researcher explained the nursing psychological support and teaching physiotherapy guideline which was discussed in two sessions and it was covered the following:

The nursing psychological support and teaching physiotherapy guideline sessions:

The nursing psychological support and teaching physiotherapy guideline had been implemented for the study group in term of sessions. The nursing psychological support and teaching physiotherapy guideline sessions aimed to evaluate the effect of nursing psychological support and teaching physiotherapy guideline on improving pain level for 
patients with TMJDs. The educational guideline was developed by the researchers based on the review of relevant literature and available resources. There were a total two sessions were conducted for each patients, each session ranged between (15-20) minutes.

Each session usually started by a summary of what had been taught during the previous session and the objectives of the new session. After each session there was 10 minutes for discussion and gave feedback. Reinforcement of teaching was performed according to patient's needs to ensure their understanding. Each patient in the study group obtains a copy of the teaching booklet. The researcher used pictures for illustration, and diagram to educate the patient.

The first session: Was started during $1^{\text {st }}$ interview at maxillofacial surgery outpatient clinic, it contains three parts:

Part I: Information about TMJs and TMJDs as definition, function, etiology, clinical manifestations of TMJDs.

Part II: Home self-care instructions with modified diet; load reduction on the TMJ is achieved by modifying the patient's diet to reduce joint loading from forces of mastication. This is achieved primarily by a non-chewing diet such as liquid or pureed food. As the joint pain improves, the diet may be advanced. Part III: Instructions about habits modification; about oral parafunctional muscle tension produced by habits such as teeth clenching, jaw thrust, gum chewing, jaw tensing and poor positioning of the head, neck, or tongue.

The second session: was started immediately after $1^{\text {st }}$ session and it contains three parts:

Part I: It contains patient education and stress control; successful management lies in awareness, patient motivation and cooperation. In stressful situations, patients were instructed to utilize stress management techniques to prevent unproductive tensing of jaw, face and neck muscles and teach patients relaxation techniques as yoga, massage, meditation, guided imagery, and slow and deep breathing exercises may be useful in calming TMJ disorders pain.

Part II: Instructions about jaw exercises and massage; includes stretching the jaw muscles by making various facial expressions and/ or range of motion exercises, making massage and moist warm towels on sensitive areas for 10-15 minutes can decrease sensitivity, pain, increase the range of mandibular movements and relaxes muscles.

Part III: Maintaining good jaw posture; while at rest, maintaining a correct jaw posture is essential for creating a harmony between the lips, face and jaw muscles, teeth, and tongue. This posture may be achieved by: Relaxing the lips and facial muscles, keeping the teeth apart, placing the tongue on the roof of the mouth behind the front teeth.

\section{Evaluation phase}

The last phase of proposed nursing psychological support and teaching physiotherapy guideline is the evaluation phase. It was done to assess the effectiveness of the nursing psychological support and teaching physiotherapy guideline on improving pain level by using the same data collection tools, and comparing the results of the data collected pre and post 4 weeks from $1^{\text {st }}$ interview after implementation of the nursing psychological support and teaching physiotherapy guideline.

\section{Ethical consideration}

The study was approved by an institutional ethics committee. An oral consent was obtained from patients to participate in the study after explanation the purpose of the study to them. The patients were informed that participation is voluntary and they could withdraw at any time of the study.

\section{Statistical analysis}

The data were tested for normality using the Anderson-Darling test and for homogeneity variances prior to further statistical analysis. Data entry was done using compatible personal computer by the researcher. Categorical variables were described by number and percent (N, \%), where continuous variables described by mean and standard deviation (Mean, SD). Chi-square test and fisher exact test used to compare between categorical variables where compare between continuous variables by t-test. A two-tailed $\mathrm{p}<0.05$ was considered statistically significant. All data was entered into statistical packages for the social sciences (SPSS) version 23.0 software for analysis. 


\section{Results}

Table (1): Frequency distribution of patients according to demographic characteristics $(\mathrm{n}=50)$.

\begin{tabular}{|l|c|c|}
\hline \multicolumn{1}{|c|}{ Variables } & No. & \% \\
\hline Age by years & \multicolumn{2}{|c|}{} \\
18-29 years & 27 & 54.0 \\
30-39 years & 17 & 34.0 \\
40-49 years & 3 & 6.0 \\
50-65 years & 3 & 6.0 \\
Mean \pm SD & \multicolumn{2}{|c|}{$\mathbf{2 9 . 1 2 \pm 9 . 8 2}$} \\
\cline { 2 - 3 } Gender & 14 & 28.0 \\
Male & 36 & 72.0 \\
Female & & \\
\hline Marital status & 27 & 54.0 \\
Single & 20 & 40.0 \\
Married & 3 & 6.0 \\
Widow & & \\
\hline Level of education & 7 & 14.0 \\
Illiterate & 4 & 8.0 \\
Read and write & 1 & 2.0 \\
Primary school & 5 & 10.0 \\
Preparatory school & 18 & 36.0 \\
Secondary school & 15 & 30.0 \\
University & & \\
\hline Occupation & 10 & 20.0 \\
Unemployed & 15 & 30.0 \\
Housewife & 13 & 26.0 \\
Student & 12 & 24.0 \\
Employer & & \\
\hline
\end{tabular}

Table (2): Distribution of the patients according to medical data for the study group $(n=50)$.

\begin{tabular}{|l|c|c|c|c|}
\hline \multicolumn{2}{|c|}{ Variables } & \multicolumn{2}{c|}{ Yes } & \multicolumn{2}{c|}{ No } \\
\cline { 2 - 5 } & $\mathbf{N}$ & $\mathbf{\%}$ & $\mathbf{N}$ & \% \\
\hline 1. Presence of trauma & & & & \\
- Motor car accident & 3 & 6.0 & 47 & 94.0 \\
- Bicycle accident & --- & --- & 50 & 100.0 \\
- Quarrel problems & 2 & 4.0 & 48 & 96.0 \\
- Assault & ---- & -- & 50 & 100.0 \\
- Athletic trauma & --- & -- & 50 & 100.0 \\
\hline Repetitive trauma & & & & \\
\hline 3. Previous surgery & ---- & --- & 50 & 100.0 \\
- Dental implants & & & & \\
- Open reduction internal fixation & 6 & 12.0 & 44 & 88.0 \\
\hline 4. Earaches & 3 & 6.0 & 47 & 94.0 \\
\hline 5. Tinnitus & 5 & 10.0 & 45 & 90.0 \\
\hline 6. Headaches & 2 & 4.0 & 48 & 96.0 \\
\hline 7. Migraines & 31 & 62.0 & 19 & 38.0 \\
\hline 8. Dizziness & 3 & 6.0 & 47 & 94.0 \\
\hline 9. Fibromyalgia & 8 & 16.0 & 42 & 84.0 \\
\hline 10. Osteoarthritis & 2 & 4.0 & 48 & 96.0 \\
\hline 11. Muscles pain & 5 & 10.0 & 45 & 90.0 \\
\hline
\end{tabular}




\begin{tabular}{|l|c|c|c|c|}
\hline \multicolumn{1}{|c|}{ Variables } & \multicolumn{2}{c|}{ Yes } & \multicolumn{2}{c|}{ No } \\
\cline { 2 - 5 } & $\mathbf{N}$ & $\mathbf{\%}$ & $\mathbf{N}$ & $\mathbf{\%}$ \\
\hline 12. Hearing changes & 1 & 2.0 & 49 & 98.0 \\
\hline 13. Neck ache & 2 & 4.0 & 48 & 96.0 \\
\hline 14. Bone pain & 12 & 24.0 & 38 & 76.0 \\
\hline 15. Ulcers & 3 & 6.0 & 47 & 94.0 \\
\hline 16. Sensitive teeth & 28 & 56.0 & 22 & 44.0 \\
\hline 17. Periodontal disease & 25 & 50.0 & 25 & 50.0 \\
\hline 18. Rheumatoid arthritis & ----- & ----- & 50 & 100.0 \\
\hline 19. Trouble sleeping & 33 & 66.0 & 17 & 34.0 \\
\hline
\end{tabular}

Table (3): Comparison of psychological state of patients pre / post 4 weeks after implementation of the nursing psychological support and physiotherapy teaching guideline $(n=50)$.

\begin{tabular}{|c|c|c|c|c|c|c|c|c|c|c|c|c|}
\hline \multirow{2}{*}{\multicolumn{2}{|c|}{ Psychological state assessment }} & \multicolumn{2}{|c|}{ Never } & \multicolumn{2}{|c|}{$\begin{array}{l}\text { Almost } \\
\text { Never }\end{array}$} & \multicolumn{2}{|c|}{ Sometimes } & \multicolumn{2}{|c|}{$\begin{array}{l}\text { Fairly } \\
\text { Often }\end{array}$} & \multicolumn{2}{|c|}{ Very Often } & \multirow{2}{*}{ P.V } \\
\hline & & $\mathbf{N}$ & $\%$ & $\mathbf{N}$ & $\%$ & $\mathbf{N}$ & $\%$ & $\mathbf{N}$ & $\%$ & $\mathbf{N}$ & $\%$ & \\
\hline \multirow{2}{*}{$\begin{array}{l}\text { 1. How often have you been upset } \\
\text { because of something that } \\
\text { happened unexpectedly? }\end{array}$} & Pre & 0 & $\begin{array}{l}0 . \\
0\end{array}$ & 0 & 0.0 & 3 & 6.0 & $\begin{array}{l}1 \\
4\end{array}$ & $\begin{array}{c}28 . \\
0\end{array}$ & $\begin{array}{l}3 \\
3 \\
\end{array}$ & 66.0 & \multirow{2}{*}{$0.001 * *$} \\
\hline & Post & 0 & $\begin{array}{l}0 . \\
0\end{array}$ & 1 & 2.0 & 23 & 46.0 & $\begin{array}{l}1 \\
2\end{array}$ & $\begin{array}{c}24 . \\
0\end{array}$ & $\begin{array}{l}1 \\
4\end{array}$ & 28.0 & \\
\hline \multirow{2}{*}{$\begin{array}{l}\text { 2. How often have you felt that you } \\
\text { were unable to control the } \\
\text { important things in your life? }\end{array}$} & Pre & 0 & $\begin{array}{l}0 . \\
0\end{array}$ & 0 & 0.0 & 30 & 60.0 & $\begin{array}{l}1 \\
0\end{array}$ & $\begin{array}{c}20 . \\
0\end{array}$ & $\begin{array}{l}1 \\
0\end{array}$ & 20.0 & \multirow{2}{*}{$0.002 * *$} \\
\hline & Post & 0 & $\begin{array}{l}0 . \\
0\end{array}$ & 8 & $\begin{array}{c}16 . \\
0\end{array}$ & 34 & 68.0 & 6 & $\begin{array}{c}12 . \\
0\end{array}$ & 2 & 4.0 & \\
\hline \multirow{2}{*}{$\begin{array}{l}\text { 3. How often have you felt nervous } \\
\text { and "stressed"? }\end{array}$} & Pre & 0 & $\begin{array}{l}0 . \\
0\end{array}$ & 0 & 0.0 & 6 & 12.0 & $\begin{array}{l}2 \\
9\end{array}$ & $\begin{array}{c}58 . \\
0\end{array}$ & $\begin{array}{l}1 \\
5\end{array}$ & 30.0 & \multirow{2}{*}{$0.001 * *$} \\
\hline & Post & 0 & $\begin{array}{l}0 . \\
0\end{array}$ & 0 & 0.0 & 37 & 74.0 & 6 & $\begin{array}{c}12 . \\
0\end{array}$ & 7 & 14.0 & \\
\hline \multirow{2}{*}{$\begin{array}{l}\text { 4. How often have you felt confident } \\
\text { about your ability to handle your } \\
\text { personal problems? }\end{array}$} & Pre & 0 & $\begin{array}{l}0 . \\
0\end{array}$ & 0 & 0.0 & 14 & 28.0 & $\begin{array}{l}1 \\
4\end{array}$ & $\begin{array}{c}28 . \\
0\end{array}$ & $\begin{array}{l}2 \\
2\end{array}$ & 44.0 & \multirow{2}{*}{$0.09 \mathrm{~ns}$} \\
\hline & Post & 0 & $\begin{array}{l}0 . \\
0\end{array}$ & 1 & 2.0 & 6 & 12.0 & $\begin{array}{l}1 \\
1\end{array}$ & $\begin{array}{c}22 . \\
0\end{array}$ & $\begin{array}{l}3 \\
2\end{array}$ & 64.0 & \\
\hline \multirow{2}{*}{$\begin{array}{l}\text { 5. How often have you felt that things } \\
\text { were going your way? }\end{array}$} & Pre & 0 & $\begin{array}{l}0 . \\
0\end{array}$ & 2 & 4.0 & 17 & 34.0 & $\begin{array}{l}1 \\
9\end{array}$ & $\begin{array}{c}38 . \\
0\end{array}$ & $\begin{array}{l}1 \\
2\end{array}$ & 24.0 & \multirow{2}{*}{$0.001 * *$} \\
\hline & Post & 0 & $\begin{array}{l}0 . \\
0\end{array}$ & 9 & $\begin{array}{c}18 . \\
0\end{array}$ & 32 & 64.0 & 5 & $\begin{array}{c}10 . \\
0\end{array}$ & 4 & 8.0 & \\
\hline \multirow{2}{*}{$\begin{array}{l}\text { 6. How often have you found that you } \\
\text { could not cope with all the things } \\
\text { that you had to do? }\end{array}$} & Pre & 0 & $\begin{array}{l}0 . \\
0\end{array}$ & 4 & 8.0 & 29 & 58.0 & 9 & $\begin{array}{c}18 . \\
0\end{array}$ & 8 & 16.0 & \multirow{2}{*}{$0.004 * *$} \\
\hline & Post & 2 & $\begin{array}{l}4 . \\
0\end{array}$ & 8 & $\begin{array}{c}16 . \\
0\end{array}$ & 37 & 74.0 & 3 & 6.0 & 0 & 0.0 & \\
\hline \multirow{2}{*}{$\begin{array}{l}\text { 7. How often have you been able to } \\
\text { control irritations in your life? }\end{array}$} & Pre & 2 & $\begin{array}{l}4 . \\
0\end{array}$ & 2 & 4.0 & 22 & 44.0 & $\begin{array}{l}2 \\
2\end{array}$ & $\begin{array}{c}44 . \\
0\end{array}$ & 2 & 4.0 & \multirow{2}{*}{$0.04 *$} \\
\hline & Post & 0 & $\begin{array}{l}0 . \\
0\end{array}$ & 2 & 4.0 & 17 & 34.0 & $\begin{array}{l}1 \\
9 \\
\end{array}$ & $\begin{array}{c}38 . \\
0\end{array}$ & $\begin{array}{l}1 \\
2 \\
\end{array}$ & 24.0 & \\
\hline \multirow{2}{*}{$\begin{array}{l}\text { 8. How often have you felt that you } \\
\text { were on top of things? }\end{array}$} & Pre & 0 & $\begin{array}{l}0 . \\
0\end{array}$ & 0 & 0.0 & 23 & 56.0 & $\begin{array}{l}1 \\
9\end{array}$ & $\begin{array}{c}38 . \\
0\end{array}$ & 2 & 4.0 & \multirow{2}{*}{$0.001 * *$} \\
\hline & Post & 0 & $\begin{array}{l}0 . \\
0\end{array}$ & 6 & $\begin{array}{c}12 . \\
0\end{array}$ & 36 & 72.0 & 6 & $\begin{array}{c}12 . \\
0\end{array}$ & $\begin{array}{l}1 \\
2\end{array}$ & 24.0 & \\
\hline \multirow{2}{*}{$\begin{array}{l}\text { 9. How often have you been angered } \\
\text { because of things that were outside } \\
\text { of your control? }\end{array}$} & Pre & 0 & $\begin{array}{l}0 . \\
0\end{array}$ & 0 & 0.0 & 8 & 16.0 & $\begin{array}{l}2 \\
1\end{array}$ & $\begin{array}{c}42 . \\
0\end{array}$ & $\begin{array}{l}2 \\
1\end{array}$ & 42.0 & \multirow{2}{*}{$0.001 * *$} \\
\hline & Post & 0 & $\begin{array}{l}0 . \\
0\end{array}$ & 2 & 4.0 & 33 & 66.0 & $\begin{array}{l}1 \\
1\end{array}$ & $\begin{array}{c}22 . \\
0\end{array}$ & 4 & 8.0 & \\
\hline \multirow{2}{*}{$\begin{array}{l}\text { 10. How often have you felt } \\
\text { difficulties were piling up so high } \\
\text { that you could not overcome them? }\end{array}$} & Pre & 0 & $\begin{array}{l}0 . \\
0\end{array}$ & 0 & 0.0 & 9 & 18.0 & $\begin{array}{l}2 \\
9\end{array}$ & $\begin{array}{c}58 . \\
0\end{array}$ & $\begin{array}{l}1 \\
2\end{array}$ & 24.0 & \multirow{2}{*}{$0.001 * *$} \\
\hline & Post & 0 & $\begin{array}{l}0 . \\
0\end{array}$ & 4 & 8.0 & 34 & 68.0 & 9 & $\begin{array}{c}18 . \\
0\end{array}$ & 3 & 6.0 & \\
\hline
\end{tabular}

Chi-Square Tests $\quad *=$ Significant difference $* p \leq 0.05 \quad * *=$ highly significance $* p \leq 0.01 \quad$ Ns $=$ Non significant difference $P>0$ 
Table (4): Comparison of perceived stress for the study group pre/post 4 weeks after implementation of the nursing psychological support and teaching physiotherapy guideline $(n=50)$.

\begin{tabular}{|c|c|c|c|c|c|}
\hline \multirow{2}{*}{ Variables } & \multicolumn{2}{|c|}{ Pre-test } & \multicolumn{2}{|c|}{ Post-test } & \multirow[b]{2}{*}{ P.V } \\
\hline & $\mathbf{N}$ & $\%$ & $\mathbf{N}$ & $\%$ & \\
\hline - Moderate stress & 13 & $26.0 \%$ & 39 & $78.0 \%$ & \multirow[b]{2}{*}{$.000 *$} \\
\hline - High perceived stress & 37 & $74.0 \%$ & 11 & $22.0 \%$ & \\
\hline
\end{tabular}

Table (5): Comparison of universal pain assessment for the study group pre/post 4 weeks after implementation of the nursing psychological support and teaching physiotherapy guideline $(n=50)$.

\begin{tabular}{|c|c|c|c|c|c|}
\hline \multirow[b]{2}{*}{ Variables } & \multicolumn{2}{|c|}{ Pre-test } & \multicolumn{2}{|c|}{ Post-test } & \multirow[b]{2}{*}{ P.V } \\
\hline & $\mathbf{N}$ & $\%$ & $\mathbf{N}$ & $\%$ & \\
\hline No pain & 1 & 2.0 & 21 & 42.0 & \multirow{5}{*}{$0.001 * *$} \\
\hline Mild pain & 8 & 16.0 & 20 & 40.0 & \\
\hline Moderate pain & 25 & 50.0 & 8 & 16.0 & \\
\hline Severe pain & 15 & 30.0 & 1 & 2.0 & \\
\hline Worst pain & 1 & 2.0 & 0 & 0.0 & \\
\hline
\end{tabular}

Chi-Square

$* *=$ highly significance $* p \leq 0.01$

Table (6): Relation between perceived stress scale and demographic data for the study group pre / post 4 weeks after implementation of the nursing psychological support and teaching physiotherapy guideline $(\mathrm{n}=$ 50).

\begin{tabular}{|c|c|c|c|c|}
\hline \multicolumn{5}{|c|}{ Perceived Stress Scale } \\
\hline Items & $\begin{array}{c}\text { Pre } \\
\text { Means } \pm \text { SD }\end{array}$ & $\begin{array}{c}\text { Post } \\
\text { Means } \pm \text { SD }\end{array}$ & P1 & $\mathbf{P 2}$ \\
\hline \multicolumn{5}{|l|}{ - Age: } \\
\hline $18-29$ & $28.77 \pm 3.65$ & $24.48 \pm 3.86$ & \multirow{5}{*}{.378} & \multirow{5}{*}{.331} \\
\hline 30-39 & $30.35 \pm 3.27$ & $23.05 \pm 3.54$ & & \\
\hline $40-49$ & $27.33 \pm 2.88$ & $27.00 \pm 6.08$ & & \\
\hline $50-65$ & $28.33 \pm 4.93$ & $23.00 \pm 1.73$ & & \\
\hline Total & $29.20 \pm 3.56$ & $24.06 \pm 3.83$ & & \\
\hline \multicolumn{5}{|l|}{ - Gender: } \\
\hline Male $=14$ & $29.50 \pm 4.25$ & $24.71 \pm 5.16$ & \multirow[t]{2}{*}{0.751} & \multirow[t]{2}{*}{.458} \\
\hline Female $=36$ & $29.08 \pm 3.32$ & $23.80 \pm 3.23$ & & \\
\hline
\end{tabular}

$N s=$ Non significant difference $P>0.05 \quad$ One Way Anova \&Independent T-Test

Table (7): Correlation between universal pain assessment and perceived stress scale for the study group pre / post 4 weeks after implementation of the nursing psychological support and teaching physiotherapy guideline $(\mathbf{n}=\mathbf{5 0})$.

\begin{tabular}{|c|c|c|c|c|c|c|c|c|c|c|}
\hline \multirow{3}{*}{ Variables } & \multicolumn{4}{|c|}{ Moderate stress } & \multicolumn{4}{|c|}{ High stress } & \multirow{3}{*}{$\frac{\text { P1 }}{\text { Pre }}$} & \multirow{3}{*}{$\begin{array}{c}\text { P2 } \\
\text { Post }\end{array}$} \\
\hline & \multicolumn{2}{|c|}{ Pre } & \multicolumn{2}{|c|}{ Post } & \multicolumn{2}{|c|}{ Pre } & \multicolumn{2}{|c|}{ Post } & & \\
\hline & $\mathbf{N}$ & $\%$ & $\mathbf{N}$ & $\%$ & $\mathbf{N}$ & $\%$ & $\mathbf{N}$ & $\%$ & & \\
\hline - No pain & 0 & 0.0 & 18 & 36.0 & 1 & 0.0 & 3 & 6.0 & \multirow{5}{*}{$.732 \mathrm{~ns}$} & \multirow{5}{*}{$.048 *$} \\
\hline - Mild pain & 4 & 8.0 & 17 & 34.0 & 4 & 8.0 & 3 & 6.0 & & \\
\hline - Moderate pain & 7 & 14.0 & 4 & 8.0 & 18 & 36.0 & 4 & 8.0 & & \\
\hline - Sever pain & 2 & 4.0 & 0 & 0.0 & 13 & 26.0 & 1 & 2.0 & & \\
\hline - Worst pain & 0 & 2.0 & 0 & 0.0 & 1 & 2.0 & 0 & 0.0 & & \\
\hline
\end{tabular}


Table (1): This table reveals that, about half of the sample of the study group their age range between 18-29 years old, with mean of (29.12 \pm 9.82$)$ and about three quarter of the study group were females $72.0 \%$, single $54.0 \%$, have secondary school $36.0 \%$ and housewife $30.0 \%$.

Table (2): This table shows that, about more than half of the study group have headache, sensitive teeth, periodontal disease and trouble sleeping (62\%, $56 \%, 50 \%$, and $66 \%$ ) respectively

Table (3): This table illustrates that, there are statistically significant differences for the study group as regard psychological state assessment except how often have you felt confident about your ability to handle your personal problems?, pre / post 4 weeks for the study group after implementation of the nursing psychological support and teaching physiotherapy guideline.

Table (4): This table demonstrates that, there are statistically significant differences for the study group as regards psychological state assessment (perceived stress scale) pre / post 4 weeks for the study group after implementation of the nursing psychological support and teaching physiotherapy guideline.

Table (5): This table shows that, there are statistically significant differences for the study group regarding universal pain assessment tool pre / post 4 weeks for the study group after implementation of the nursing psychological support and teaching physiotherapy guideline.

Table (6): This table illustrates that, there are no statistically significant differences for the study group as regards perceived stress scale with age and gender pre / post 4 weeks for the study group after implementation of the nursing psychological support and teaching physiotherapy guideline.

Table (7): This table illustrates that, there are positive correlation between universal pain assessment and perceived stress scale for the study group $\left(\mathrm{P} . \mathrm{V}=0.048^{*}\right)$ post 4 weeks after implementation of the nursing psychological support and teaching physiotherapy guideline.

\section{Discussion}

Temporomandibular joint disorders (TMJDs) are an umbrella term for a number of conditions in the area of the joint, temple, and masticatory system (Alkhudhairy et al., 2018). The proper function of (TMJ) depends upon the harmony of the different structures of the TMJ (including mandibular condyles, meniscus, glenoid fossa, ligaments, and muscles). The TMJ continues in its function as usual until it is disturbed by external influences that affect the function of the joint, such as mechanical, psychological, occupational, and habits (Al Shaban \& Gul Abdul Waheed, 2018).

Regarding demographic characteristics of the patients; the present study clarified that, maximum percentage of patients with TMJ disorders was between the age ranges of 18-29 years old. This finding consistent with (Al Shaban \& Gul Abdul Waheed, 2018) who revealed that, maximum percentage of patients was between the age ranges of 19-29 years old. In disagreements with (Marklund \& Wänman, 2010 and Yekkalam \& Wänman, 2014) who have demonstrated that, the frequency of TMJDs symptoms varies with age, as it increased greatly between $20-40$ years and in adolescents, then declined after 50 years of age. In the researcher view increasing age during adolescence to young adulthood may be related to changes and challenges that exposed to them.

Also the incidence of female was more than male regarding TMJ disorders which are consistent with most of the studies (Fernandes et al., 2016 \& Murad et al., 2016) which have shown clearly the predominance of the female with TMJ disorders.

Also (Hirsch et al., 2012) who reported in their study, the predominance of the female with TMJ disorders during pubertal development, but the diagnosis remains unknown and more researches are needed to try to demonstrate the relationship between female hormones and TMJ disorders (cause and effect). While according to (Kim et al., 2012), there is a tendency of female patients to be predisposed to TMJDs more than male patients.

In disagreement with (Lee et al., 2013) reported in their study, the predominance of the male with TMJ disorders; another study (Modi et al., 2012) concluded that no significant relationship between females and males regarding TMJ disorders.

In the researcher view the reason of higher prevalence of TMJDs among females than males because females more sensitive and perceive more stress than males as stress during pubertal development, family habits and the mores and values of the community.

Regarding to medical data; the results of the present study revealed that, about more than half of the study group have headache, sensitive teeth, periodontal disease and trouble sleeping. These results are in the same line with (Graff-Radford\& Abbott, 2016) who reported that, TMJDs involving muscle pain predisposes to migraines and chronic daily headaches and the more painful the TMJDs, the more likely it is to be associated with headache. According to (Smith et al., 2013), some patients may have a history of headaches resistant to treatment; therefore, the TMJDs trigger should not be overlooked in such patients. 
In the researcher view numbers of factors have been studied in relation to TMJDs, such as dental status, number of teeth, parafunctions, clicking, locking of the jaws, and a history of trauma. These factors considered risk factors and may have an effect in the development of TMJDs.

As regard psychological state assessment (stress on the PSS); the study illustrated statistically significant differences for the study group except how often have you felt confident about your ability to handle your personal problems. This results in agreement with (Alkhudhairy et al., 2018) who showed a statistically significant association between "how often have you been upset because of something that happened unexpectedly?" as well as "how often have you found that you could not cope with all the things that you had to do?" , but the same study revealed disagreement about "How often have you felt confident about your ability to handle your personal problems? " in which the researcher revealed statistically significant difference.

Also the study demonstrated that, there are statistically significant differences for the study group as regards psychological state assessment (perceived stress) in agreement with (Rai and Kaur, 2013 \& Salameh et al., 2015) who showed in their results of case-control study significant differences between patient and control groups regarding perceived stress scale.

Concerning universal pain assessment; also the data reveals that, there are statistically significant differences for the study group regarding universal pain assessment tool. According to (Campos et al., 2008) has reported significant associations between intra articular disorder stages and jaw pain. Conversely, according to (Palconet et al., 2012) did not find an association between intra articular disorder stages and TMJ pain.

In the researcher view pain is the most important symptom of TMJDs, and considered the main reason for patients to seek medical help. Most patients suffer from pain during mandibular movements, at rest, or on palpation of the muscles and the nursing psychological support and teaching physiotherapy guideline were revealed effectiveness in improving pain level.

As regard relation of perceived stress scale with age and gender for the study group, the present study demonstrated no statistically significant differences for the study group as regards perceived stress scale with age and gender pre / post 4 weeks after implementation of the nursing psychological support and teaching physiotherapy guideline in agreement with (Yoon et al., 2012) in which a frequency difference analysis of the low- and high- risk groups by gender did not reveal a significant difference and no significant difference was observed in the comparison of the mean stress level and stress group distribution based on age groups.

Also the present study illustrated positive correlation between universal pain assessment and perceived stress scale for the study group after implementation of the nursing psychological support and teaching physiotherapy guideline in agreement with (Pierson, 2011) found the same result and, in addition, stated that parallel relationship between stress levels and pain intensity can be observed and it appears when stress levels decrease, symptoms of TMJDs decrease, and vice versa. As that emotional and mental stress correlated with the amount of pain the patient was experiencing.

According to (Kindler et al., 2012) stated that, psychological factors can initiate muscle hyperactivity, followed by biomechanical changes and consequent pain. They can also produce neurotransmitters serotonin and catecholamines imbalance, inducing pain and according to (Jerjes et. al., 2008) who mentioned that, TMJDs can create a cycle where stress causes bruxism, which causes pain, and that pain then affects the quality of life, causing more stress.

In the researcher view, stress is how body reacts to and handle harmful situations, and more stressful situations can be harmful to our health. Stress and TMJ are often linked to each other as symptoms of stress often manifest in physical manifestations. So more coping strategies of dealing with stress must be learn and teaches to avoid more disorders affect our body and health.

\section{Conclusion}

It was concluded that nursing psychological support and teaching physiotherapy are an important factors in the treatment of temporomandibular joint disorders.

Based on the findings of present study, the following recommendations are suggested:

1. Continuous schedule programs to improve and increase patient's knowledge and awareness about manifestations of temporomandibular joint disorders and its prevention.

2. A written teaching hand book should be available for each patient in simplified term about parafunctional habits that consider an important factor that increase the risk of having temporomandibular joint disorders.

3. Patient education sessions are recommended to learn patients how cope with daily living stress. 


\section{References}

1. Alkhudhairy, M., Al Ramel, F., Al Jader, G., Al Saegh, L., Al Hadad, A., Alalwan, T., \& Al Bandar, M., (2018): A self-reported association between temporomandibular joint disorders, headaches, and stress. Journal of International Society of Preventive \& Community Dentistry, 8(4):pp.371-380.

2. AlShaban, K., \& Gul Abdul Waheed, Z., (2018): Prevalence of TMJ Disorders among the Patients Attending the Dental Clinic of Ajman University of Science and Technology-Fujairah Campus, UAE. International journal of dentistry, V.2018.P.6

3. Augusto, V., Perina, K., Penha, D., Santos, D., \& Oliveira, V., (2016): Temporomandibular dysfunction, stress and common mental disorder in university students. Acta ortopedica brasileira, 24(6): pp.330-333.

4. Campos, M., Campos, P., Cangussu, M., Guimarães, R., \& Line, S., (2008): Analysis of magnetic resonance imaging characteristics and pain in temporomandibular joints with and without degenerative changes of the condyle. International journal of oral and maxillofacial surgery, 37(6): pp.529-534.

5. Chisnoiu, A., Lascu, L., Pascu, L., Georgiu, C., \& Chisnoiu, R., (2015): Emotional stress evaluation in patients with temporomandibular joint disorder. Human and Veterinary Medicine, 7(2): pp.104-107.

6. Cohen, S., Kamarck, T., \& Mermelstein, R., (1983): A global measure of perceived stress. Journal of Health and Social Behavior, 24, pp. 386-396.

7. De Kanter, R., Battistuzzi, P., \& Truin, G., (2018): Temporomandibular Disorders: "Occlusion" Matters. Pain research \& management, V. 2018, P. 13.

8. Fernandes, G., Franco-Micheloni, A., Siqueira, J., Goncalves, D., \& Camparis, C., (2016): Parafunctional habits are associated cumulatively to painful temporomandibular disorders in adolescents. Brazilian oral research, 30(1):P.15.

9. Gil-Martínez, A., Paris-Alemany, A., Lópezde-Uralde-Villanueva, I., \& La Touche, R., (2018): Management of pain in patients with temporomandibular disorder (TMD): challenges and solutions. Journal of pain research, 11, pp.571-587.

10. Graff-Radford, S., \& Abbott, J., (2016): Temporomandibular Disorders and
Headache. Oral Maxillofac Surg Clin North Am. 28 (3):pp.335-349.

11. Hirsch, C., Hoffmann, J., \& Türp, J., (2012): Are temporomandibular disorder symptoms and diagnoses associated with pubertal development in adolescents? An epidemiological study. Journal of Orofacial Orthopedics/Fortschritte der Kieferorthopädie, 73(1):pp. 6-18.

12. Jain, R., Yadav, A., Rastogi, S., \& Patel, S., (2016): Management of temporomandibular disorder: A review. Journal of Advanced Medical and Dental Sciences Research, 4(5):pp. 126-131.

13. Jerjes, W., Upile, T., Abbas, S., Kafas, P., Vourvachis, M., Rob, J., \& Hopper, C., (2008): Muscle disorders and dentition-related aspects in temporomandibular disorders: controversies in the most commonly used treatment modalities. International archives of medicine, 1(1): pp.23-35.

14. Kim, Y., Kim, S., Im, J., \& Yun, P., (2012): Clinical survey of the patients with temporomandibular joint disorders, using Research Diagnostic Criteria (Axis II) for TMD: preliminary study. Journal of CranioMaxillofacial Surgery, 40(4): pp.366-372.

15. Kindler, S., Samietz, S., Houshmand, M., Grabe, H., Bernhardt, O., Biffar, R., \& Schwahn, C., (2012): Depressive and anxiety symptoms as risk factors for temporomandibular joint pain: a prospective cohort study in the general population. The Journal of Pain, 13(12): pp.1188-1197.

16. Lee, J., Kim, Y., Kim, S., \& Yun, P., (2013): "Evaluation of Korean teenagers with temporomandibular joint disorders," Journal of the Korean Association of Oral and Maxillofacial Surgeons, 39(5): pp. 231-237.

17. Macres, S., Moore, P., Fishman, S., (2013): Acute pain management. In: Barash PG, Cullen BF, Stoelting RK, et al., eds. Clinical Anesthesia. 7th ed. Philadelphia: Lippincott Williams \& Wilkins, pp.1611-1642.

18. Marklund, S., \& Wänman, A., (2010): Risk factors associated with incidence and persistence of signs and symptoms of temporomandibular disorders. Acta Odontologica Scandinavica, 68(5): pp.289-299.

19. Modi, P., Shaikh, S., \& Munde, A., (2012): A cross sectional study of prevalence of temporomandibular disorders in university students. Int J Sci Res Publ, 2(9):pp. 1-3.

20. Murad, B., Sepah, N., Rehman, B., \& Ahmad, T., (2016): Parafunctional habits among undergraduate clinical students and 
house officers at Khyber College of Dentistry. Journal of Khyber College of Dentistry, 6(2):pp. 20-24.

21. Okeson, J., (2019): Management of Temporomandibular Disorders and OcclusionE-Book. Mosby.

22. Paco, M., Peleteiro, B., Duarte, J., \& Pinho, T. (2016): The effectiveness of physiotherapy in the management of temporomandibular disorders: a systemic review and meta-analysis. J Oral Facial Pain Headache, 30(3):pp.210-220

23. Palconet, G., Ludlow, J., Tyndall, D., \& Lim, P., (2012): Correlating cone beam CT results with temporomandibular joint pain of osteoarthritic origin. Dentomaxillofacial Radiology, 41(2): pp.126-130.

24. Pierson, M., (2011): Changes in temporomandibular joint dysfunction symptoms following massage therapy: a case report. International journal of therapeutic massage \& bodywork, 4(4): pp.37-47.

25. Rai, B., \& Kaur, J., (2013): Association between stress, sleep quality and temporomandibular joint dysfunction: simulated Mars mission. Oman Medical Journal, 28(3): pp.216-219.

26. Salameh, E., Alshaarani, F., Hamed, H., \& Nassar, J., (2015): Investigation of the relationship between psychosocial stress and temporomandibular disorder in adults by measuring salivary cortisol concentration: A case-control study. The Journal of the Indian Prosthodontic Society, 15(2): pp.148-152.

27. Smith, S., Mir, E., Bair, E., Slade, G., Dubner, R., Fillingim, R., \& Maixner, W., (2013): Genetic variants associated with development of TMD and its intermediate phenotypes: the genetic architecture of TMD in the OPPERA prospective cohort study. The Journal of Pain, 14(12): pp.91-101.

28. Yekkalam, N., \& Wänman, A., (2014): Prevalence of signs and symptoms indicative of temporomandibular disorders and headaches in $35-, \quad 50-, \quad 65$-and 75-year-olds living in Västerbotten, Sweden. Acta Odontologica Scandinavica, 72(6): pp.458-465.

29. Yoon, H., Lee, S., Hur, J., Kim, H., Seok, J., Kim, H., \& Huh, J., (2012): Relationship between stress levels and treatment in patients with temporomandibular disorders. Journal of the Korean Association of Oral and Maxillofacial Surgeons, 38(6): pp.326-331. 